\title{
Commentary on "Effects of Early Musical Experience on Auditory Sequence Memory" by Adam Tierney, Tonya Bergeson, and David Pisoni
}

\author{
E. GLENN SCHELLENBERG \\ University of Toronto
}

\begin{abstract}
Tierney, Bergeson, and Pisoni (2008) conclude that their results "provide additional converging evidence that early musical experience and activity-dependent learning may selectively affect verbal rehearsal processes and the allocation of attention in sequence memory tasks". Closer inspection of their methods and results, the methods and results of previous studies, and the literature as a whole makes it clear that these conclusions are unfounded.
\end{abstract}

Submitted 2008 September 16; accepted 2008 September 24.

OVER the past 15 years, much empirical research has been motivated by the hypothesis that formal training in music has nonmusical cognitive benefits. It is now well established (for reviews see Schellenberg, 2005, 2006a) that taking music lessons is associated positively with performance on tasks that measure abilities in the domains of language (e.g., Marques, Moreno, Castro, \& Besson, 2007; Moreno et al., 2008; Patel \& Iversen, 2007), spatial reasoning (Hetland, 2000), mathematics (Vaughn, 2000), memory (e.g., Jakobson, Lewycky, Kilgour, \& Stoesz, 2008; Lee, Lu, \& Ko, 2007), full-scale IQ (FSIQ; Schellenberg, 2004, 2006b), and virtually any other domain one chooses to study (e.g., Hughes \& Franz, 2007; Stoesz, Jakobson, Kilgour, \& Lewycky, 2007). The simplest explanation of the available data is that children with high FSIQs are more likely than other children to take music lessons and to do well on any test they are given (Schellenberg, 2006b). Nonetheless, many scholars, including Tierney, Bergeson, and Pisoni (2008) and most of those cited above, continue to promote the notion of links between music training and specific sub-areas of intellectual functioning, which is tantamount to failing to see the forest (i.e., the big picture) for the trees (i.e., minor details; see Schellenberg \& Peretz, 2008).

In order to conclude that there are special links between music lessons and cognitive abilities that cannot be attributed to FSIQ, researchers need to provide evidence that such links are evident when FSIQ is held constant. To date, there is not a single example of this result in the literature. Rather, in some instances, researchers provide evidence that music and nonmusic groups differ on the "specific" outcome variable of interest while holding constant an additional variable that has a modest association with FSIQ. As an illustrative example, Jakobson et al. (2008) and Stoesz et al. (2007) reported that musically trained participants outperformed their untrained counterparts on nonmusical cognitive abilities, including verbal memory (Jakobson et al., 2008), even after holding constant performance on a test that required participants to pronounce irregularly spelled words (e.g., cello, debt, epitome). High-FSIQ individuals would undoubtedly score well on this pronunciation test, as they do on virtually every test (Deary, 2000), but it is equally obvious that a test of pronunciation is a poor substitute for a test of FSIQ. The availability of relatively quick-to-administer measures that correlate strongly with FSIQ (e.g., Wonderlic Personnel Test, Wonderlic, 1999; Kaufman Brief Intelligence Test, Kaufman \& Kaufman, 2004), make the authors' choice of this control variable curious, to say the least.

An alternative strategy, such as the one taken by Tierney et al. (2008), attempts to show that associations with music lessons are evident on one task but not on another. The particular additional test used by Tierney et al. was a self-report measure of word familiarity, which has untested reliability, almost no evidence of validity (except for Stallings, Kirk, Chin, \& Gao, 2000), and no established association with FSIQ. Nevertheless, even if the test were indeed a reliable and valid substitute for FSIQ, one can never prove the null hypothesis if groups fail to differ significantly. Indeed, a glance at Tierney et al.'s Fig. 2 (i.e., with the music group performing best on each of the three word-familiarity categories) suggests that with a modest increase in sample size and statistical power, the music group would have outperformed the three nonmusic groups. An even more egregious example of this approach came from Chan, Ho, and Cheung (1998), who, like Tierney et al., reported that musically trained individuals have better verbal memory than their untrained counterparts. Their groups also differed in years of education, a finding that was swept under the rug by lowering the alphalevel to .01. At a more typical level of .05 , the authors could have concluded only that better-educated (and higher-IQ) individuals are (1) more likely to take music lessons and (2) superior on a test of verbal memory. In general, the observed alpha-value should be extremely high (i.e., $>.5$, not simply $>.05$ or $>.01$ ) before one can 
predict with any confidence that, even if the groups do indeed differ in their respective populations, such a difference is almost certain to be trivial (see Schellenberg \& Trehub, 2008).

Tierney et al. (2008) also imply that their results provide support for the proposal that music lessons cause improvements in verbal memory, which could not be further from the truth. As they note, there is only one study to date (i.e., with random assignment and appropriate control conditions) that allowed for inferences of causation between music and cognitive abilities (Schellenberg 2004). But Schellenberg's results do not preclude the extremely likely possibility that causation typically goes in the reverse direction (from FSIQ to music lessons). Tierney et al. further imply that correlational studies and quasi-experiments differ with respect to causal inferences, which again is completely false. Neither design has random assignment to the IV nor allows for inferences of causation. Finally, merely citing evidence of brain differences between musically trained and untrained participants - as in Tierney et al. and many other reports - does nothing to settle the issue of causation. Admittedly, the positive association between years of exposure and the extent of cortical representations for the left hand of string players (Elbert, Pantev, Wienbuch, Rockstroh, \& Taub, 1995) suggests quite strongly - but not unequivocally - that experience is shaping brain structure and function, but examples this clear are exceptions in the literature. If pre-existing individual differences in cognitive ability affect the likelihood of taking music lessons or acquiring absolute pitch (e.g., Schlaug, Jäncke, Huang, \& Steinmetz, 2005), as I propose, such differences must be instantiated somewhere in the brain.

On a more positive note, Tierney et al. (2008) included comparison groups (gymnasts, video gamers) that can be thought of as matched to musically trained participants, at least on some levels (e.g., intensive experience and practice, motor skills). Unfortunately, the groups are unlikely to be matched on FSIQ. In short, the evidence provided by Tierney et al. does not support the proposal that taking music lessons enhances a specific sub-area of cognitive ability.

\section{REFERENCES}

Deary, I. J. (2001). Intelligence: A very short introduction. Oxford, UK: Oxford University Press.

Elbert, T., Pantev, C., Wienbruch, C., Rockstroh, B., \& Taub, E. (1995). Increased cortical representation of the fingers of the left hand in string players. Science, Vol. 270, 305-307.

Hetland, L. (2000). Learning to make music enhances spatial reasoning. Journal of Aesthetic Education, Vol. 34, No. $3 / 4,179-238$.

Hughes, C. M. L, \& Franz, E. A. (2007). Experience-dependent effects in unimanual and bimanual reaction time tasks in musicians. Journal of Motor Behavior, Vol. 39, 3-8.

Jakobson, L. S., Lewycky, S. T., Kilgour, A. R., \& Stoesz, B. M. (2008). Memory for verbal and visual material in highly trained musicians. Music Perception, Vol. 26, 41-55.

Kaufman, A. S., \& Kaufman, N. L. (2004). Kaufman brief intelligence test (2nd ed.). Circle Pines, MN: American Guidance Service.

Lee, Y., Lu, M., \& Ko, H. (2007). Effects of skill training on working memory capacity. Learning and Instruction, Vol. 17, 336-344.

Marques, C., Moreno, S., Castro, S. L. \& Besson, M. (2007). Musicians detect pitch violation in a foreign language better than nonmusicians: Behavioral and electrophysiological evidence. Journal of Cognitive Neuroscience, Vol. 19, 1453-1463.

Moreno, S., Marques, C., Santos, A., Santos, M., Luís Castro, S., \& Besson, M. (2008). Musical training influences linguistic abilities in 8-year-old children: More evidence for brain plasticity. Cerebral Cortex, in press.

Patel, A. D., \& Iversen, J. R. (2007). The linguistic benefits of musical abilities. Trends in Cognitive Sciences, Vol. 11, 369-372.

Schellenberg, E. G. (2004). Music lessons enhance IQ. Psychological Science, Vol. 15, 511-514. 
Schellenberg, E. G. (2005). Music and cognitive abilities. Current Directions in Psychological Science, Vol. 14, 322-325.

Schellenberg, E. G. (2006a). Exposure to music: The truth about the consequences. In G. E. McPherson (Ed.), The child as musician: A handbook of musical development (pp. 111-134). Oxford, UK: Oxford University Press.

Schellenberg, E. G. (2006b). Long-term positive associations between music lessons and IQ. Journal of Educational Psychology, Vol. 98, 457-468.

Schellenberg, E. G., \& Peretz, I. (2008). Music, language, and cognition: Unresolved issues. Trends in Cognitive Sciences, Vol. 12, 45-46.

Schellenberg, E. G., \& Trehub, S. E. (2008). Is there an Asian advantage for pitch memory? Music Perception, Vol. 25, 241-252.

Schlaug, G., Jäncke, L., Huang, Y., \& Steinmetz, H. (2005). In vivo evidence of structural brain asymmetry in musicians. Science, Vol. 267, 699-701.

Stallings, L. M, Kirk, K. I., Chin, S. B., \& Gao, S. (2000). Parent word familiarity and the language development of pediatric cochlear implant users. Volta Review, Vol. 102, 237-258.

Stoesz, B. M., Jakobson, L. J., Kilgour, A. R., \& Lewycky, S. T. (2007). Local processing advantage in musicians: Evidence from disembedding and constructional tasks. Music Perception, Vol. 25, 153-165.

Vaughn, K. (2000). Music and mathematics: Modest support for the oft-claimed relationship. Journal of Aesthetic Education, Vol. 34, No. 3/4, 149-166.

Wonderlic, E. (1999). Wonderlic personnel test and scholastic level exam, user's manual. Libertyville, IL: Wonderlic, Inc. 